\title{
Immunologic Effects of National Cholesterol Education Panel Step-2 Diets with and without Fish-derived N-3 Fatty Acid Enrichment
}

\author{
Simin Nikbin Meydani, Alice H. Lichtenstein, Stephen Cornwall, Mohsen Meydani, Barry R. Goldin, * Helen Rasmussen, \\ Charles A. Dinarello, ${ }^{\ddagger}$ and Ernst J. Schaefer \\ United States Department of Agriculture-Human Nutrition Research Center on Aging at Tufts University; ${ }^{*}$ Department of Community \\ Health, Tufts University School of Medicine, and ${ }^{\ddagger}$ Department of Medicine, New England Medical Center, Boston, Massachusetts 02111
}

\begin{abstract}
Reductions in dietary fat, saturated fat, and cholesterol have been recommended to reduce the risk of heart disease in our society. The effects of these modifications on human cytokine production and immune responses have not been well studied. $\mathbf{2 2}$ subjects $>\mathbf{4 0} \mathrm{yr}$ of age were fed a diet approximating that of the current American (14.1\% of calories as saturated fatty acids, [SFA], 14.5\% monounsaturated fatty acids [MUFA], 6.1\% [n-6] polyunsaturated fatty acids [PUFA], 0.8\% [n-3] PUFA, and $147 \mathrm{mg}$ cholesterol /1,000 calories) for $6 \mathrm{wk}$, after which time they consumed ( 11 in each group) one of the two low-fat, low-cholesterol, high-PUFA diets based on National Cholesterol Education Panel (NCEP) Step 2 recommendations (4.0-4.5\% SFA, 10.8-11.6\% MUFA, 10.3-10.5\% PUFA, 45$61 \mathrm{mg}$ cholesterol / 1,000 calories) for 24 wk. One of the NCEP Step 2 diets was enriched in fish-derived (n-3) PUFA (low-fat, high-fish: $0.54 \%$ or $1.23 \mathrm{~g} / \mathrm{d}$ eicosapentaenoic acid [EPA] and docosahexaenoic acid [DHA] [121-188 $\mathrm{g}$ fish/d]) and the other low in fish-derived (n-3) PUFA (low-fat, low-fish [0.13\% or $0.27 \mathrm{~g} / \mathrm{d}$ EPA and DHA] [33 $\mathrm{g}$ fish/d]). Measurements of in vivo and in vitro indexes of immune responses were taken after each dietary period. Long-term feeding of low-fat, lowfish diet enriched in plant-derived PUFA increased blood mononuclear cell mitogenic response to the $T$ cell mitogen Con $A$, IL-1 $\beta$, and TNF production and had no effect on delayed-type hypersensitivity skin response, IL-6, GM-CSF, or PGE 2 production. In contrast, the low-fat, high-fish diet significantly decreased the percentage of helper $T$ cells whereas the percentage of suppressor $\mathbf{T}$ cells increased. Mitogenic responses to Con $\mathbf{A}$ and delayed-type hypersensitivity skin response as well as the production of cytokines IL-1 $\beta$, TNF, and IL-6 by mononuclear cells were significantly reduced after the consumption of the low-fat, high-fish diet $(24,40,45,35$, and $34 \%$, respectively; $P$ $<0.05$ by two-tailed Student's $t$ test except for IL-1 $\beta$ and TNF, which is by one-tailed $t$ test ). Our data are consistent with the concept that the NCEP Step 2 diet that is high in fish significantly decreases various parameters of the immune response in contrast to this diet when it is low in fish. Such alterations may be beneficial for the prevention and treatment of atherosclerotic and inflammatory diseases but may be detrimental with
\end{abstract}

Address reprint requests to Simin Nikbin Meydani, DVM, PhD, Nutritional Immunology Laboratory, USDA-Human Nutrition Research Center on Aging at Tufts University, 711 Washington Street, Boston, MA 02111.

Received for publication 26 August 1992 and in revised form 22 February 1993.

The Journal of Clinical Investigation, Inc.

Volume 92, July 1993, 105-113 regard to host defense against invading pathogens. ( $J$. Clin. Invest. 1993. 92:105-113.) Key words: NCEP Step 2 - n-3 PUFA • n-6 PUFA • immune response cytokines • cholesterol

\section{Introduction}

Many organizations have recommended reductions in the dietary fat, saturated fatty acids, and cholesterol to reduce the risk of heart disease $(1,2)$. The National Cholesterol Education Panel (NCEP) ${ }^{1}$ as part of its Step 2 diet has recommended a fat intake of $<30 \%$ of calories, $<7 \%$ of calories from saturated fatty acids, $10-15 \%$ of calories from monounsaturated fatty acids, and $\leq 10 \%$ of calories from polyunsaturated fatty acids (PUFA), with a cholesterol intake of $<200 \mathrm{mg} / \mathrm{d}$. To date, the effect of these recommendations on the immune response has not been well studied, although studies indicate that the quantity and quality of dietary fat can alter the immune response (for review see references 3-6). These include changes in the production of immunologic mediators, i.e., cytokines, prostanoids, and in vitro lymphocyte proliferation, in response to mitogens. Some of these same mediators have been implicated in the pathogenesis of atherosclerosis (7-10).

We therefore studied the effect of long-term (24-wk) feeding of low-fat, low-cholesterol, moderately high PUFA diets (NCEP Step 2) with or without fish-derived ( $n-3$ ) PUFA on in vitro and in vivo indexes of the immune response of healthy normolipidemic volunteers. We report here that the long-term feeding of NCEP Step 2 diets enriched in eicosapentaenoic acid (EPA) and docosahexaenoic acid (DHA) decreases ex vivo cytokine production, proliferative response of peripheral blood mononuclear cells to the $T$ cell mitogen Con A, percentage of $T$ helper cells, and the delayed-type hypersensitivity skin test, an in vivo measure of cell-mediated immunity. In contrast, feeding NCEP Step 2 diets low in EPA and DHA but moderately high in plant derived ( $n-6)$ and ( $n-3)$ PUFA increased mitogenic response to Con A and ex vivo IL- $1 \beta$ and TNF production and had no significant effect on other parameters measured.

\section{Methods}

\section{Subjects}

22 normolipidemic and normotensive volunteers ( 11 women and 11 men) over the age of 40 underwent a complete medical history and physical examination. The subjects had no evidence of any chronic illness including endocrine, hepatic, renal, thyroid, or cardiac dysfunc-

1. Abbreviations used in this paper: DHA, docosahexaenoic acid; EPA, eicosapentaenoic acid; MUFA, monounsaturated fatty acids; NCEP, National Cholesterol Education Panel; PUFA, polyunsaturated fatty acids. 
Table I. Subject Characteristics

\begin{tabular}{lccccc}
\hline & \multicolumn{2}{c}{ Low-fat, high-fish } & & \multicolumn{2}{c}{ Low-fat, low-fish } \\
\cline { 2 - 3 } \cline { 6 - 6 } \cline { 5 - 6 } & Men & Women & & Men & Women \\
\hline Subject number & 3 & 7 & & 7 & 4 \\
Age (yr) & $66 \pm 5$ & $65 \pm 2$ & & $56 \pm 6$ & $71 \pm 2$ \\
Weight (kg) & $79 \pm 3$ & $60 \pm 4$ & & $74 \pm 3$ & $73 \pm 6$ \\
Body mass index & $26.2 \pm 0.9$ & $25.5 \pm 3.8$ & & $24.8 \pm 2.0$ & $27.1 \pm 4.3$ \\
& & & & & \\
\hline
\end{tabular}

Mean \pm SE.

tion. They did not smoke nor were they taking medications known to affect plasma lipid levels ( cholestyramine, colestipol, niacin, clofibrate, gemfribrozil, probucol, lovastatin, beta blockers, thiazide, diuretics, diphenyl-hydantoin, cis-retinoic acid, ascorbic acid, estrogens, progestins, anabolic steroids, hydrocortisone, fish-oil capsules, or thyroxine) or nonsteroidal antiinflammatory drugs such as aspirin and indomethacin. Compliance was monitored by measurement of plasma total fatty acid levels every 4 wk as described below. One male subject was excluded from the study because his plasma fatty acid profile did not show the anticipated changes. The age, weight, and body mass index for subjects are shown in Table I. No attempt was made to sex match the subjects for the two dietary periods. Previous work has shown that fish-oil supplementation induces similar changes in cytokine production in males and females $(11,12)$.

\section{Experimental protocol}

The experimental protocol was approved by the Human Investigation Review Committee of the New England Medical Center and Tufts University. The 30-wk study period was divided into two diet phases (Fig. 1). All food was provided by the study. The first phase was a 6-wk period during which the subjects consumed a diet approximating that of the current American (baseline). The second phase was a 24-wk period during which subjects either consumed a low-fat, low-cholesterol diet conforming to the NCEP Step 2 recommendations enriched in EPA and DHA ( $0.54 \%$ of calories or $1.23 \mathrm{~g} / \mathrm{d}$ ) (low-fat, high-fish) (Table II) $(n=11)$ or consumed the same diet low in EPA and DHA $(0.13 \%$ of calories or $0.27 \mathrm{~g} / \mathrm{d})$ (low-fat, low-fish) (Table II) $(n=11)$. The rest of ( $n-3)$ PUFA in the two diets was provided as linolenic acid $(18: 3 n-3)$. First 11 subjects completed the baseline diet and low-fat, high-fish phases. Then 11 subjects ( 8 new and 3 who had completed the high-fish diet) completed the baseline and low-fat, low-fish phases. The subjects entered the study at different time points to avoid seasonal effects. A maximum break of 4 wk could be taken by study subjects between the baseline and low-fat diet phases. The three subjects who participated in both dietary treatments did so with $\geq 6$-mo intervals between the two studies. All diets were prepared in the Metabolic Re-

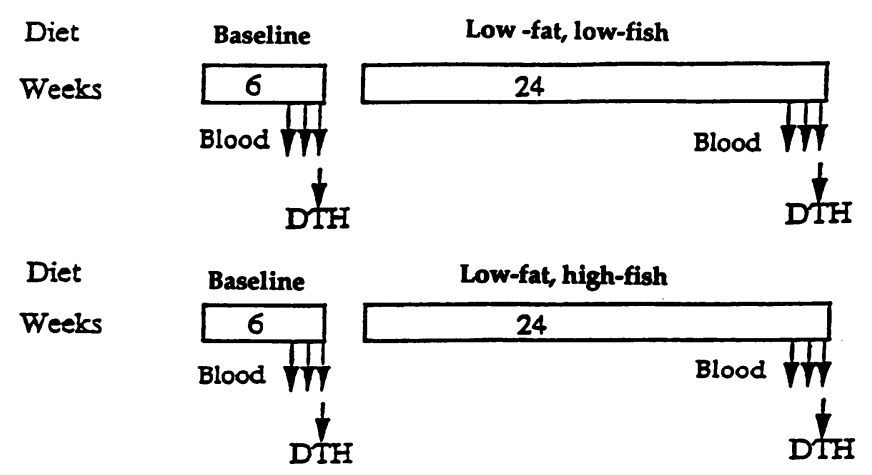

Figure 1. Experimental design.
Table II. Fat Composition of Baseline and Low-Fat Diets Low and High in Fish*

\begin{tabular}{|c|c|c|c|}
\hline Nutrient & Baseline & Low-fat, high-fish & Low-fat, low-fish \\
\hline & \multicolumn{3}{|c|}{$\%$ of calories } \\
\hline Fat & $35.4 \pm 2.3$ & $26.4 \pm 2.0$ & $25.2 \pm 0.8$ \\
\hline Saturated & $14.1 \pm 2.2$ & $4.5 \pm 0.7$ & $4.0 \pm 0.4$ \\
\hline Mono-unsaturated & $14.5 \pm 1.0$ & $11.6 \pm 1.4$ & $10.8 \pm 0.4$ \\
\hline Poly-unsaturated & $6.9 \pm 1.2$ & $10.3 \pm 0.2$ & $10.5 \pm 0.2$ \\
\hline$n-6$ & $6.1 \pm 1.0$ & $8.0 \pm 0.9$ & $8.8 \pm 0.4$ \\
\hline $\mathrm{n}-3$ & $0.8 \pm 0.6$ & $2.4 \pm 0.3$ & $1.8 \pm 0.2$ \\
\hline$n-6 / n-3$ & 7.3 & 3.6 & 4.9 \\
\hline $\mathrm{n}-6 / \mathrm{EPA}+\mathrm{DHA}^{\ddagger}$ & 200 & 12.5 & 50 \\
\hline
\end{tabular}

Mean $\pm \mathrm{SD} ; n=3$. ${ }^{*}$ Chemical analysis performed by Hazelton Laboratories, except for EPA and DHA, which were calculated using USDA Provisional Tables (13). ${ }^{\ddagger}$ EPA, eicosapentaenoic acid; DHA, docosahexaenoic acid.

search Unit kitchen at the USDA-Human Nutrition Research Center on Aging at Tufts University and were composed entirely of natural foods consumed as three meals and one or two snacks per day.

A 3-d cycle menu consisting of food items normally consumed by average Americans was designed to meet the requirements of each dietary period. The menu consisted of breakfast, lunch, dinner, and one or two snacks. A typical menu for baseline period included coffee, cereal, whole milk, or bagel and cream cheese or white bread and butter, canned fruits and orange juice for breakfast; mixed salad, juice, turkey or roast beef for lunch; crackers, peanut butter, and whole milk for afternoon snack; corn, carrots, salad, beverage, sirloin steak, chicken or filet of sole, and bread for dinner; and strawberries, yogurt, or applesauce for an after dinner snack. The amount of cholesterol and fat and composition of fat was adjusted by inclusion of butter, heavy cream, olive oil, mayonnaise, soybean oil, walnuts or walnut oil, and egg yolks. At this phase, fish was served about two times per week ( 200 $\mathrm{g} / \mathrm{wk}$ ), red meat six times per week, and chicken or turkey about four times per week.

A typical menu for the low-fat, high-fish period included cereal, fruit, coffee, skim milk, bagel or white bread, and jelly for breakfast; tuna, turkey breast, salad or vegetable soup, bread or crackers, fruit, fruit juice, or beverage for lunch; filet of sole or salmon or chicken, vegetables, salad, juice, fruits, and walnuts for dinner; peanut butter, crackers, skim milk, and fruits for snacks. At this phase, fish was served eight times per week (121-188 g/d) and turkey or chicken four times per week.

Typical menu for the low-fat, low-fish period included fruits, coffee, fruit juice, cereal, bagel or bread with soybean margarine and jelly, and skim milk for breakfast; vegetable soup or salad, tuna or turkey breast or nonmeat chili, fruits, juice, and bread for lunch; turkey, vegetables, salad, bread, and walnuts for dinner; and peanut butter, crackers, fruit, and skim milk for snacks. At this phase, fish was served about two times per week $(200 \mathrm{~g} / \mathrm{wk})$ and turkey about eight times per week. To increase the level of $18: 3 n-3$ soybean margarine, rapeseed oil and walnuts were used.

Subjects were required to report to the Metabolic Research Unit a minimum of five times per week and to eat at least one meal per visit at the unit. All other food and drink was packaged for take-out. A dietitian was on call at all times in the event that problems arose. A supply of an entire 3-d food cycle was provided for the volunteers to accommodate emergency situations that might have prevented a volunteer from picking up the scheduled meals. During each visit body weight and blood pressure were measured. Calorie levels were assigned so that the subjects neither gained nor lost weight. The Grand Forks database (GRAND, release 8606) was used to calculate the nutrient composi- 
tion of the diets and analytical data from Hazelton Laboratories (Madison, WI) was used as confirmation, except for EPA and DHA, which were calculated using USDA Provisional tables (13). The diets had similar percentages of protein and carbohydrates, which were $15 \pm 1.2$ and $49.4 \pm 2.2 \%$ for baseline; $17 \pm 0.9$ and $56.1 \pm 2.9 \%$ for low-fat, highfish; and $17 \pm 0.1$ and $57.9 \pm 0.8 \%$ for low-fat, low-fish diets, respectively. Fat composition of diets is shown in Table II. Cholesterol content of the three diets was $147 \pm 27.0,61.0 \pm 15.9$, and $45.0 \pm 9.6 \mathrm{mg} / 100 \mathrm{kcal}$ for baseline; low-fat, high-fish; and low-fat, low-fish diets, respectively.

Blood samples were collected after a 12 -h fast during weeks 4,5 , and 6 of the baseline diet period and weeks 22,23, and 24 of either of low-fat diet periods for in vitro immunologic and biochemical measurements (Fig. 1). When the blood collections for each period were completed subjects were administered a delayed-type hypersensitivity skin test as described below.

Delayed-type hypersensitivity skin test. Delayed-type hypersensitivity skin test was assessed with Multi Test-CMI (Merieux Institute, Inc., Miami, FL), with a single-use disposable applicator of acrylic resin with eight heads loaded with glycerine control and the following seven recall antigens: tetanus toxoid, diphtheria toxoid, Streptococcus (group C), Mycobacterium tuberculosis, Candida albicans, Trichophyton metagrophytes, and Proteus mirabilis. The diameter of positive reactions was measured at 24 and $48 \mathrm{~h}$ after administration of the test. The antigen score was calculated as the total number of positive antigens and the cumulative score was calculated as the total diameter of induration of all positive reactions. An induration of $\geq 2 \mathrm{~mm}$ was considered positive. If a positive reaction to the glycerine control was observed, the diameter of its induration was subtracted from all the other positive reactions. The test was administered by the same nurse for both the baseline and low-fat, high-and-low fish periods for each subject and the diameter of induration was measured by the same person at the end of each dietary period. The Multi Test-CMI rather than the conventional skin test was used to avoid the boosting effect observed with repeated administration (14).

Isolation of mononuclear cells. Peripheral blood mononuclear cells were separated from heparinized blood as previously described (11). Cells were washed twice in RPMI 1640 supplemented with $100 \mathrm{U} / \mathrm{ml}$ penicillin, $100 \mu \mathrm{g} / \mathrm{ml}$ streptomycin, $2 \mathrm{mmol} / 1 \mathrm{~L}$-glutamine, and 25 mmol/1 Hepes (Gibco Laboratories, Grand Island, NY). RPMI 1640 used in this study was subjected to ultrafiltration to remove endotoxin as previously described (15). Cells were resuspended in medium and counted under a light microscope. Cell viability was assessed using trypan blue exclusion. Cells were then suspended at appropriate concentrations for measurement of mitogenic lymphocyte proliferation, induction of cytokines, and $\mathrm{PGE}_{2}$ synthesis. A sample of heparinized plasma was heat inactivated at $56^{\circ} \mathrm{C}$ for $30 \mathrm{~min}$ to be used as autologous plasma in the cell cultures. Autologous plasma rather than fetal bovine serum was used as this is rich in AA and can influence fatty acid composition of cell membrane.

Lymphocyte proliferation. Lymphocyte proliferation was measured by $\left[{ }^{3} \mathrm{H}\right]$ thymidine incorporation after stimulation with $\mathrm{T}$ and $\mathrm{B}$ cell mitogens. Dilutions of mitogens from 10 to $300 \mu \mathrm{g} / \mathrm{ml}$ for Con A (Sigma Chemical Co., St. Louis, MO), PHA (Difco Laboratories, Detroit, MI) and B cell mitogen Staphylococcus aureus Cowan I (Zysorbin 10\% suspension; Zymed Laboratories Inc., San Francisco, CA) were prepared in endotoxin-free RPMI 1640 with $10 \%$ autologous plasma and optimal dilution for each mitogen was determined. $100 \mu \mathrm{l}$ of each mitogen was added in triplicate into 96-well, flat-bottomed microtiter plates (Becton-Dickinson \& Co., Oxnard, CA). Cells were suspended at $10^{6}$ cells $/ \mathrm{ml}$ in RPMI 1640. $100 \mu$ l of the cell suspension was then added to wells with and without mitogens and incubated for $72 \mathrm{~h}$ at $37^{\circ} \mathrm{C}$ in an atmosphere of $5 \% \mathrm{CO}_{2}$ and $95 \%$ humidity. $4 \mathrm{~h}$ before termination of incubation, $0.5 \mu \mathrm{Ci}$ of $\left[{ }^{3} \mathrm{H}\right]$ thymidine (specific activity 6.7 Ci $/ \mathrm{mmol}$; New England Nuclear, Boston, MA) in $20 \mu \mathrm{l}$ was added to each well. Cells were harvested onto glass microtiter filter paper using a cell harvester (PHD, Cambridge, MA). Filter disks were placed in mini vials and counted in a liquid-scintillation counter (Beckman Instruments, Inc., Palo Alto, CA ). The results are reported as corrected cpm: the average cpm of mitogen-stimulated cultures minus the average cpm of cultures without mitogens. The scintillation counter had an efficiency of $45 \%$ for tritium.

$I L-2, I L-6$, and GM-CSF. $10^{6}$ cells/ml in RPMI 1640 with $10 \%$ autologous plasma (final concentration) were cultured in 24-well flatbottomed plates (Becton Dickinson \& Co.) with Con A ( $10 \mu \mathrm{g} / \mathrm{ml} \mathrm{final}$ concentration ) for $48 \mathrm{~h}$. Cell-free supernatant was stored at $-70^{\circ} \mathrm{C}$ for later analysis of IL-2, IL-6, and GM-CSF. IL-2 activity was measured using a microassay method described by Gillis et al. (16). Recombinant human IL-2 (Genzyme Corp., Boston, MA) was used as standard. $1 \mathrm{U} / \mathrm{ml}$ was defined as the amount of recombinant IL-2 that causes a half-maximal incorporation of $\left[{ }^{3} \mathrm{H}\right]$ thymidine in $5 \times 10^{3}$ cytotoxic $\mathrm{T}$ cell line (CTLL) cells in culture. IL-2 activity was calculated using probit analysis (15). CTLL cells were a gift from Dr. S. Gillis of Immunex, Inc. (Seattle, WA ). IL-6 and GM-CSF were measured by RIA as previously described $(17,18)$.

$I L-1$ and TNF. Mononuclear cells were suspended at $5 \times 10^{6}$ cells/ $\mathrm{ml}$ in RPMI with $2 \%$ autologous plasma ( $1 \%$ final concentration). This cell suspension $(0.5 \mathrm{ml})$ was added to $0.5 \mathrm{ml}$ RPMI or RPMI containing heat-killed Staphylococcus epidermis (S. epi.) (at 20 organisms per cell final concentration) or LPS (Escherichia coli 0111:B4, Sigma Chemical Co., St. Louis, MO) ( $1 \mathrm{ng} / \mathrm{ml}$ final concentration ) for $24 \mathrm{~h}$. The plates were frozen until the end of the study, at which time all plates from each donor were thawed and exposed to two more freezethaw cycles to complete cell lysis (19). The contents of wells, consisting of cell lysates and supernatants, were analyzed by RIA for IL-1 $\beta$ and TNF as previously described $(19,20)$. Each RIA is specific for the respective cytokine and does not cross-react with IL-1, GM-CSF, IFN$\alpha,-\beta$, or $\gamma$.

$P G E_{2}$ production. Mononuclear cells $\left(10^{6}\right.$ cells $\left./ \mathrm{ml}\right)$ were cultured in 24-well flat-bottomed plates (Becton Dickinson \& Co.) in the presence or absence of different concentrations of PHA and 10\% autologous plasma for $48 \mathrm{~h}$ in a $37^{\circ} \mathrm{C}, 5 \% \mathrm{CO}_{2}$ humidified incubator. Cell-free supernatant was saved at $-70^{\circ} \mathrm{C}$ for $\mathrm{PGE}_{2}$ analysis by RIA as described by McCosh et al. (21). PGE ${ }_{2}$ antibody was a gift from Dr. J. Dupont of Iowa State University and Dr. M. Mathias of Colorado State University. The antibody cross-reactivity and specificity have been described (22). Cytokine and PGE ${ }_{2}$ RIA as well as mitogen responses were performed on coded samples by blinded technicians.

Complete blood count, white cell differential, and flow cytometric analysis. Complete blood count was obtained using a hematology analyzer (model Baker 9000; Serono-Baker Instrument Inc., Allentown, PA) (23) and white cell differential was assessed by microscopic examination of blood smears after Wright-Giemsa staining. For flow cytometric analysis, cells were suspended at a concentration of $10^{7} \mathrm{cell} / \mathrm{ml}$ in cold PBS with $0.1 \%$ sodium azide and $2 \%$ fetal calf serum. $50 \mu \mathrm{l}$ of suspended cells was incubated with $10 \mu \mathrm{l}$ each of the following monoclonal antibodies: anti-Leu-3a FITC (CD4+), anti-Leu-2a FITC $(\mathrm{CD} 8+)$, and anti-Leu-4 PE (CD3+) (Becton Dickinson \& Co.) for $30-45 \mathrm{~min}$ on ice. After incubation, $2 \mathrm{ml}$ of cold PBS (containing $0.1 \%$ sodium azide and $2 \%$ fetal calf serum) was added to the cell and gently vortexed. Cells were centrifuged at $300 \mathrm{~g}$ for $5 \mathrm{~min}$ at $2-8^{\circ} \mathrm{C}$. The washing procedure was repeated two more times with $1 \mathrm{ml}$ PBS. Cells were then resuspended in $0.5 \mathrm{ml}$ PBS with $0.1 \%$ sodium azide and $2 \%$ fetal calf serum and kept on ice until flow cytometric analysis by FACS $® C A N$ (Becton Dickinson \& Co.) as described (24). Gates were set at 2. The ratio of forward scatter to side scatter was 6 .

Plasma tocopherol. Plasma samples were saved under nitrogen at $-70^{\circ} \mathrm{C}$ for tocopherol analysis. Plasma was analyzed by a modified HPLC method of Bieri et al. (25) as previously described (26).

Fatty acid analysis. The transesterification and analysis of plasma fatty acids were performed as previously described (11). The fatty acids methyl esters of over 40 fatty acids (C13:0-C28:0, including cis- and trans-configurations) are separated by this method. Peaks were identified and the procedure was validated by chromatography of mixtures of authenticated fatty acids methyl esters. Data were normalized by comparing the areas of the fatty acids peaks with the area of the internal standard peak, heptadecanoic acid, after correction for the various re- 
Table III. Effect of Long-Term Consumption of Low-Fat Diets Low and High in Fish on Plasma Fatty Acid Composition

\begin{tabular}{lccccc}
\hline Fatty acid & Baseline & Low-fat, high-fish & $P$ & Baseline & Low-fat, low-fish \\
\hline \multicolumn{7}{c}{ \% normalized } \\
$18: 2 \mathrm{n}-6$ & $32.00 \pm 1.10$ & $33.7 \pm 0.66$ & 0.003 & $35.93 \pm 1.40$ & $34.91 \pm 1.42$ \\
$18: 3 \mathrm{n}-3$ & $0.60 \pm 0.03$ & $1.2 \pm 0.07$ & 0.0002 & $0.48 \pm 0.06$ & $1.03 \pm 0.16$ \\
$20: 4 \mathrm{n}-6$ & $8.20 \pm 0.47$ & $5.9 \pm 0.30$ & 0.0001 & $8.32 \pm 0.029$ & $7.31 \pm 0.52$ \\
$20: 5 \mathrm{n}-3$ & $0.70 \pm 0.10$ & $2.8 \pm 0.23$ & 0.0001 & $0.54 \pm 0.05$ & $0.83 \pm 0.11$ \\
$22: 6 \mathrm{n}-3$ & $3.00 \pm 0.23$ & $5.2 \pm 0.30$ & 0.0001 & $1.95 \pm 0.10$ & $2.45 \pm 0.24$ \\
Total n-3 & $4.27 \pm 0.25$ & $9.23 \pm 0.49$ & 0.0000 & $2.95 \pm 0.19$ & 0.001 \\
AA/EPA & $12.12 \pm 0.51$ & $2.12 \pm 0.25$ & 0.0001 & $16.45 \pm 1.02$ & 0.003 \\
& & & & & 0.08 \\
& & & & & \\
\end{tabular}

* Mean \pm SE; numbers represent percentage of identified fatty acids (see text).

sponse factors. The values presented are calculated as percentages of the total area of the identified fatty acids peaks.

Statistical analysis. In vitro tests were performed for each subject on three different occasions at the end of each dietary period. The means of these three measurements were used for analysis. Means and SE for each dietary period were calculated using the SAS (Statistical Analysis System) PROC GLM (General Linear Models) procedure (27) and were compared by Student's paired $t$ test or Wilcoxon signed rank test depending on distribution of the data. For all measurements in each group $n=10$ and 11 for high- and low-fish periods, respectively, unless otherwise indicated. A one-tailed $t$ test was used in determining the probability of significant changes induced by high-fish diet in production of IL-1 $\beta$ and TNF. Previous studies have shown that fish oil decreased production of these cytokines, therefore, the null hypothesized for these parameters was set to test if a high-fish diet will decrease production of these cytokines.

\section{Results}

Plasma fatty acids. Compliance was assessed in part by monitoring plasma fatty acids. The low-fat, high-fish diet produced significant increase in plasma linoleic acid $(18: 2 \mathrm{n}-6)(5 \%, P$ $=0.003)$, linolenic acid $(100 \%, P=0.002)$, EPA $(20: 5 n-3)$ (313\%), DHA (22:6n-3) (73\%), and total (n-3) PUFA (116\%) as well as a significant decrease in AA $(18: 4 n-6)(28 \%)(P$ $=0.0001$ for all $)$ (Table III) and in the AA/EPA ratio $(82 \%, P$ $=0.0001)$ (Table III). Plasma saturated fatty acids $(14: 0,16: 0$, 18:0) and monounsaturated fatty acids (18:1n-9) were significantly decreased (data not shown). Of the 11 subjects who completed the low-fat, high fish diet, only one did not show the expected change in fatty acid profile, indicating noncompliance. His data were excluded from all calculations. No signif- icant change in linolenic or DHA was observed in subjects consuming the low-fat, low-fish diet. However, we observed a significant increase in plasma linolenic $(115 \%, P=0.001)$, EPA $(54 \%, P=0.004)$, and total $(\mathrm{n}-3)$ PUFA $(34 \%, P$ $=0.002)$ and a decrease in AA $(12 \%, P=0.003)$ and in the AA $/$ EPA ratio ( $37 \%, P=0.002$ ) (Table III). Plasma myristic (14:0) and stearic (18:0) fatty acids were significantly decreased while the $18: 1 \mathrm{n}-9$ level was significantly increased (3\%) (data not shown). Detailed plasma fatty acids and lipoprotein analysis will be reported separately $(28,29)$. The mean reduction by low-fat, high-fish diet in total cholesterol, LDL, HDL, and triglycerides was $14,15,12$, and $7 \%$, respectively. The mean reduction by low-fat, low-fish diet was 19,20 , and $16 \%$ in total cholesterol, LDL, and HDL, and there was $5 \%$ increase in triglycerides. No significant change in total cholesterol/HDL ratio was observed.

Plasma tocopherol. Plasma tocopherol concentrations are shown in Table IV. No significant change in plasma tocopherol level was observed after consumption of low-fat, high-fish diet. A small (5\%) but significant decrease was noted in subjects consuming low-fat, low-fish diet. The significant decrease is lost if tocopherol concentration is expressed as a function of plasma total cholesterol and triglycerides. This is a reflection of changes in plasma cholesterol and triglyceride after the consumption of low-fat diets $(28,29)$. Since the function of tocopherol is to protect PUFA from oxidation we felt it was more appropriate to evaluate changes in plasma tocopherol level as a function of changes in plasma PUFA. When this was done both low-fat diets caused a small decrease in tocopherol/PUFA ratio $(6 \%, P=0.08$ for low-fat, low-fish diet and $10 \%, P=0.04$ for low-fat, high-fish diet) (Table IV).

Table IV. Effect of Low-Fat Diets High and Low in Fish on Plasma Tocopherol Concentration*

\begin{tabular}{|c|c|c|c|c|c|c|}
\hline $\begin{array}{l}\text { Plasma } \\
\text { tocopherol }\end{array}$ & Baseline & Low-fat, high-fish & $P$ & Baseline & Low-fat, low-fish & $P$ \\
\hline$\mu \mathrm{g} / \mathrm{dl}$ plasma & $943 \pm 64$ & $979 \pm 80$ & 0.14 & $1025 \pm 65$ & $959 \pm 71$ & 0.02 \\
\hline$\mu \mathrm{g} /$ total chol $+\mathrm{TG}^{\ddagger}$ & $3.1 \pm 0.2$ & $3.6 \pm 2.1$ & 0.01 & $3.3 \pm 0.1$ & $3.4 \pm 0.04$ & 0.67 \\
\hline $\begin{array}{l}\mu \mathrm{g} / \text { no. of double } \\
\text { bonds in plasma } \\
\text { fatty acid }{ }^{\S}\end{array}$ & $8.0 \pm 0.5$ & $7.2 \pm 1.8$ & 0.04 & $7.1 \pm 0.5$ & $6.7 \pm 0.6$ & 0.08 \\
\hline
\end{tabular}

${ }^{*}$ Mean \pm SE; $n=9$. ${ }^{\ddagger}$ TG, triglyceride; chol, cholesterol. ${ }^{\S}$ Calculated using percent of each fatty acid in plasma multiplied by number of double bonds in each fatty acid. 
Table V. Effect of Low-Fat Diets High and Low in Fish on Ex Vivo Cytokine and PGE Production

\begin{tabular}{|c|c|c|c|c|c|c|}
\hline & Baseline & Low-fat, high-fish & Percent change & Baseline & Low-fat, low-fish & Percent change \\
\hline & \multicolumn{2}{|c|}{$n g / m l$} & \multicolumn{4}{|c|}{$n g / m l$} \\
\hline \multicolumn{7}{|l|}{ IL-1 $\beta^{*}$} \\
\hline LPS & $5.71 \pm 1.02$ & $3.44 \pm 0.78^{\prime \prime}$ & -40 & $4.28 \pm 1.49$ & $6.93 \pm 1.64^{\prime \prime}$ & 62 \\
\hline S. epi. & $15.64 \pm 3.24$ & $11.64 \pm 2.74$ & -25 & $13.3 \pm 1.5$ & $16.32 \pm 2.53$ & 23 \\
\hline \multicolumn{7}{|l|}{$\mathrm{TNF}^{*}$} \\
\hline LPS & $4.71 \pm 0.91$ & $4.36 \pm 1.04^{\| \prime}$ & -7 & $5.79 \pm 0.79$ & $8.56 \pm 1.67^{\pi}$ & 47 \\
\hline S. epi. & $13.9 \pm 2.59$ & $8.98 \pm 2.04$ & -35 & $8.18 \pm 1.92$ & $9.56 \pm 1.70$ & 17 \\
\hline GM-CSF ${ }^{*}$ & $1.42 \pm 0.19$ & $1.02 \pm 0.17$ & -28 & $1.58 \pm 0.24$ & $1.59 \pm 0.28$ & 0.6 \\
\hline IL-6 $6^{\ddagger}$ & $1.14 \pm 0.13$ & $0.75 \pm 0.08^{1}$ & -34 & $0.75 \pm 0.20$ & $0.75 \pm 0.26$ & 0 \\
\hline \multicolumn{7}{|l|}{$\mathrm{PGE}_{2}^{\S}$} \\
\hline Control & $0.37 \pm 0.18$ & $0.08 \pm 0.02$ & -78 & $0.17 \pm 0.05$ & $0.17 \pm 0.06$ & 0 \\
\hline PHA $(10 \mu \mathrm{g} / \mathrm{ml})$ & $0.76 \pm 0.24$ & $0.28 \pm 0.08$ & -63 & $1.98 \pm 1.01$ & $2.59 \pm 1.86$ & 30 \\
\hline PHA $(100 \mu \mathrm{g} / \mathrm{ml})$ & $1.31 \pm 0.29$ & $0.42 \pm 0.11^{\prime \prime}$ & -67 & $2.59 \pm 1.85$ & $3.94 \pm 2.14$ & 52 \\
\hline
\end{tabular}

Values represent mean $\pm \mathrm{SE}$. ${ }^{*} 5 \times 10^{6}$ cells were stimulated with $1 \mathrm{ng} / \mathrm{ml} \mathrm{LPS}$ or 20 organisms per cell of $S$. epi. for $24 \mathrm{~h}$ (three measurements at each time point). ${ }^{\ddagger} 10^{6}$ cells $/ \mathrm{ml}$ were cultured with $10 \mu \mathrm{g} / \mathrm{ml}$ Con A for $48 \mathrm{~h}$ (three measurements at each time point). ${ }^{\S} 10^{6}$ cells $/ \mathrm{ml} \mathrm{were}$ cultured in the presence or absence of 10 or $100 \mu \mathrm{g} / \mathrm{ml}$ PHA for $48 \mathrm{~h}$ (three measurements at each time point). " $P=0.03$ and $P=0.04 \mathrm{for}$ IL- $1 \beta$ and TNF, respectively, by paired one-tailed Student's $t$ test. ' $P<0.05$ by paired two-tailed Student's $t$ test.

$P G E_{2}$. After consumption of the low-fat, high-fish diet, spontaneous and PHA-stimulated cultures produced less $\mathrm{PGE}_{2}$ compared with the baseline diet period ( Table V). The percent decrease in $\mathrm{PGE}_{2}$ production after the low-fat, high-fish period for spontaneous, 10 , and $100 \mu \mathrm{g} / \mathrm{ml}$ PHA was 79,63 , and $68 \%$, respectively. However, these differences were only statistically significant for those cultures stimulated with $100 \mu \mathrm{g} / \mathrm{ml}$ PHA $(P=0.02)$. Spontaneous or PHA-stimulated $\mathrm{PGE}_{2}$ production was not affected by the low-fat, low-fish diet (Table V).

White blood cell number and subpopulations. There was no statistically significant change in total number of WBC, lymphocytes, monocytes, or polymorphonuclear leukocytes as indicated by differential cell counts associated with the consumption of either diet (data not shown). The percentage of $\mathrm{T}$ cells $(\mathrm{CD} 3+)$ was not affected by diet. Samples from five of the subjects who consumed low-fat, high-fish diet were available for FACS ${ }^{\circledR}$ analysis; however, all five subjects tested showed a decrease in the percentage of CD4+ cells and an increase in percentage of CD8 + cells after 24 wk of consuming the low-fat, high-fish diet. Subjects fed low-fat, low-fish diet showed a significant decrease in the percentage of CD8+ $(P<0.05, n=11)$ cells and a nonsignificant increase in CD4+ cells (Table VI).

Cytokine production. LPS- and $S$. epi-stimulated IL- $1 \beta$ production was reduced after consumption of low-fat, high-fish $\operatorname{diet}$ (40\% [ $P=0.07$ using two-tailed $t$ test or $P=0.035$ using one tailed $t$ test, $n=9$ ] and 25\% [ $P=0.3$ ] decrease, respectively) (Table V). Decrease in $S$. epi.-stimulated TNF production was also observed after consumption of the low-fat, highfish diet (35\% decrease, $P=0.08$ using two-tailed $t$ test or $P$ $=0.04$ using one-tailed $t$ test) (Table V). The low-fat, low-fish diet, however, caused a significant increase in LPS-stimulated IL- $1 \beta$ production (62\% increase, $P=0.003$ ) (Table V) and LPS-stimulated TNF production ( $47 \%$ increase, $P=0.03$ ) ( Table V).

GM-CSF production was not significantly affected by either diet (Table V), whereas IL-6 production was reduced after consumption of the low-fat, high-fish diet (34\% decrease, $P$ $=0.03$ ) $($ Table $\mathrm{V}) .7$ out of 10 subjects showed a decrease in
IL-2 production after consumption of the low-fat, high-fish diet, but the decrease in IL-2 production did not reach statistical significance. The reverse was observed in subjects consuming the low-fat, low-fish diet, i.e., a nonsignificant increase in IL-2 production was observed (data not shown).

Mitogenic response and delayed-type hypersensitivity skin response. Mitogenic responses to the $\mathrm{T}$ cell mitogens Con $\mathrm{A}$ and PHA were reduced after consumption of a low-fat, highfish diet (24\% decrease, $P=0.03$ for Con A and 30\% decrease, $P=0.1$ for PHA) (Fig. $2 A$ and data not shown). Consumption of a low-fat, low-fish diet on the other hand increased mitogenic response (28\% increase for Con $\mathrm{A}, P=0.057$, and $15 \%$ increase for PHA) (Fig. $2 B$ and data not shown). Although mitogenic responses to PHA or Con A in the two dietary groups were not significantly different at baseline (after 6 wk of the baseline diet), subjects consuming the low-fat, high-fish diet had significantly lower mitogenic responses to Con A ( $56 \%$ lower, $P=0.057$ ) and PHA ( $53 \%$ lower, $P=0.002$ ) than those who consumed low-fat, low-fish diets. The mitogenic response to the B cell mitogen $S$. aureus Cowan I was not affected by either diet (data not shown). As depicted in Fig. $2 C$, delayedtype hypersensitivity skin response was affected by the highfish diet. The induration index was significantly reduced after the low-fat, high-fish diet period (45\% decrease, $P=0.009$ ).

Table VI. Effect of Low-Fat Diets High and Low in Fish on T Cell Subpopulations

\begin{tabular}{lcccc}
\hline Baseline & $\begin{array}{c}\text { Low-fat, high-fish } \\
(n=5)\end{array}$ & Baseline & $\begin{array}{c}\text { Low-fat, low-fish } \\
(n=11)\end{array}$ \\
\hline \multicolumn{5}{c}{$\%$} \\
$\mathrm{CD}_{4+}$ & $46.3 \pm 6.5$ & $40.0 \pm 4.8^{*}$ & $41.7 \pm 4.1$ & $46.5 \pm 3.8$ \\
$\mathrm{CD}_{8+}$ & $28.2 \pm 7.5$ & $44.3 \pm 6.2^{\ddagger}$ & $32.7 \pm 4.6$ & $27.9 \pm 3.9^{*}$ \\
\hline
\end{tabular}

Mean \pm SEM. ${ }^{*} P<0.05$ by paired Student's $t$ test. ${ }^{\ddagger} P<0.06$ by paired Student's $t$ test. 

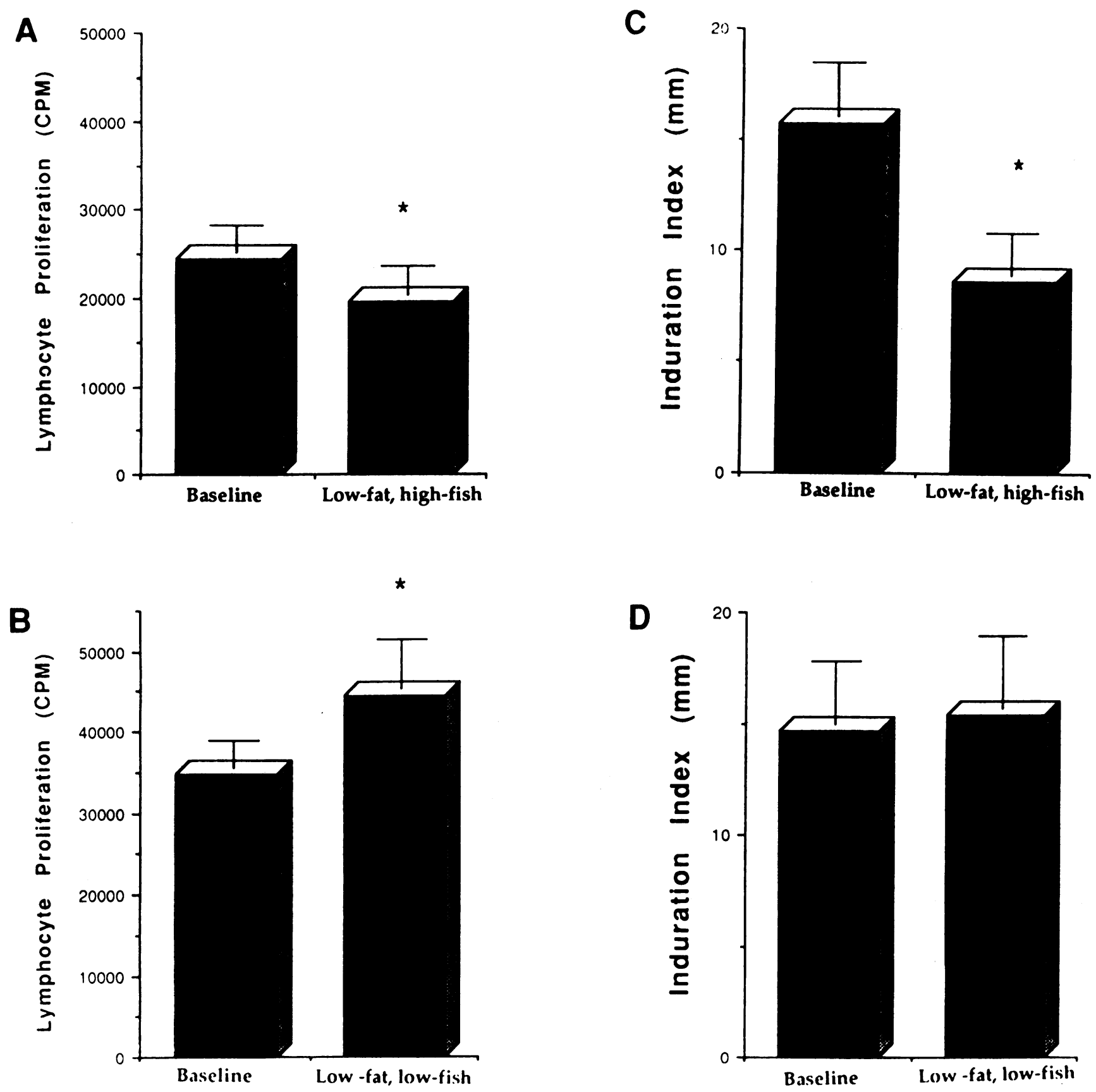

\section{DIET}

\section{DIET}

Figure 2. Effect of low-fat diets high $(A$ and $C)$ and low $(B$ and $D)$ on lymphocyte proliferation and delayed-type hypersensitivity skin response. For lymphocyte proliferation, $10^{6} \mathrm{PBMC} / \mathrm{ml}$ were stimulated with $50 \mu \mathrm{g} / \mathrm{ml}$ (final concentration) Con A for $72 \mathrm{~h}$ (three measurements at each time point). Lymphocyte proliferation was measured by incorporation of $\left[{ }^{3} \mathrm{H}\right]$ thymidine into DNA after a 4-h pulse. Data represent corrected $\mathrm{cpm}$, which is the cpm of stimulated culture minus $\mathrm{cpm}$ of unstimulated culture. There was no difference in cpm of unstimulated cultures between the two different time points. Values represent mean \pm SE. *Significantly different from baseline values at $P=0.03(A)$ for high-fish diet and $P=0.057(B)$ for low-fish diet as determined by paired Student's $t$ test. Delayed-type hypersensitivity skin response was measured by administration of seven antigens in the form of Multi Test CMI (see Methods) after baseline and after each of the low-fat diets. Diameter of induration was measured $48 \mathrm{~h}$ after administration. Cumulative index was measured by adding the diameter of all the positive responses (induration diameter of $\geq 2 \mathrm{~mm}$ ). Values represent mean \pm SE. *Significantly different from baseline values at $P=0.009(C)$ by paired Student's $t$ test.

Nine subjects showed a decrease in the induration index. The total number of positive responses to different antigens was reduced in $50 \%$ of the subjects. No significant change in de- layed-type hypersensitivity skin response was observed in subjects consuming low-fat, low-fish diet (Fig. $2 \mathrm{D}$ ) with $54 \%$ of subjects showing an increase in this response. Although the 
delayed-type hypersensitivity skin response of the two dietary groups was not significantly different from each other at baseline, the delayed-type hypersensitivity skin response of subjects consuming low-fat, high-fish diet was one half that of those who consumed low-fat, low-fish $\operatorname{diet}(P=0.01)$.

\section{Discussion}

Our results demonstrate that long-term feeding of low-fat, lowcholesterol moderately high PUFA diets has significant effects on several parameters of immune and inflammatory responses of normolipidemic subjects. The nature of the effect, however, is influenced by the type of PUFA. Diets enriched in (n-3) PUFA derived from fish significantly reduced delayed-type hypersensitivity skin response, mitogenic response to Con A, percent helper T cells, IL-6, IL-1 $\beta$ (one tailed $t$ test), TNF (one tailed $t$ test), and $\mathrm{PGE}_{2}$ production and caused a nonsignificant reduction in GM-CSF and IL-2 production. Consumption of essentially the same diet but low in fish-derived ( $n-3)$ PUFA, however, increased mitogenic response to Con A, IL-1 $\beta$, and TNF production, decreased percent cytotoxic/suppressor $T$ cells, and had no effect on delayed-type hypersensitivity skin response and percentage of helper T cells, IL-6, GM-CSF, and $\mathrm{PGE}_{2}$ production.

Low-fat, low-cholesterol moderately high PUFA diets are recommended to reduce the risk of heart disease due to their hypocholesterolemic effect $(1,2)$. It has been suggested that cytokines secreted by activated monocytes or the cells of the vessel walls might mediate many of the pathophysiological changes in the foam cells of vessel wall associated with atherogenesis. IL-1 and TNF promote adherence of leukocytes to endothelial cells and stimulate smooth muscle cell proliferation $(7,8)$. Furthermore, these cytokines have been shown to change the hemostatic balance of endothelial cells in vitro so that their surface changes from one of an antithrombotic to one of a procoagulant state $(30,31)$. Recent studies show that oxidized lipids stimulate IL-1 production (32). In the present studies, long-term feeding of diets low in total fat, saturated fat, and enriched in ( $n-3)$ PUFA was associated with decreased production of IL- $1 \beta$, TNF, and IL- 6 , suggesting that in addition to their hypolipidemic effects, these diets could reduce the risk of atherosclerotic diseases by their reduction of the proinflammatory and proliferative cytokines. Epidemiological studies indicate that consumption of fish and fish oil is associated with a low rate of coronary heart disease (33). Prospective studies and controlled human trials also indicate that dietary fish protects against heart disease and reduced mortality after myocardial infarction (34). Decreased cytokine and $\mathrm{PGE}_{2}$ synthesis in patients given EPA supplementation are associated with a reduction in the severity of arthritis and ulcerative colitis $(35,36)$. Previous work documenting similar decreases in cytokine production in healthy volunteers $(11,12)$ provided EPA and DHA in the form of fish-oil supplements. It is noteworthy that the changes reported in the present studies were the result of consumption of EPA and DHA from natural foods in levels not considered extreme $(121-188 \mathrm{~g} / \mathrm{d}$ in the form of tuna, filet of sole, and salmon). We also observed that long-term intake of low-fat, high-fish diets is associated with a significant reduction in the percentage of helper $\mathrm{T}$ cells, mitogenic response to $\mathrm{T}$ cell mitogens, and delayed-type hypersensitivity skin response. These parameters are often used as indicators of host defense against various diseases. It is not clear whether the decreases observed in helper T cells, GM-CSF (49\%), IL-6 (33\%), mitogenic response (24\%), and delayed-type hypersensitivity skin response $(46 \%)$ after consumption of low-fat, high-fish diets are sufficient to compromise the immune response. Published studies to date have shown that true anergy is associated with increased mortality risk $(37,38)$. However, correlations between a 50\% decrease in these parameters and the risks of infection or cancer are lacking. Animal studies, however, indicate that these changes might have clinical significance. Fish-oil feeding decreased the natural resistance of mice to infection with Salmonella typhimurium (39) and rats fed diets containing $9 \%$ menhaden oil had a shorter life span compared with those fed corn oil or beef tallow (40). Rabbits given a high fish diet for $7 \mathrm{~d}$ after birth had decreased lung clearance of inspired Staphylococcus aureus by $50 \%$ compared with saline control or low doses of the oil (41). Fish oil-fed mice had a reduced capacity for cytotoxicity of mastocytoma cells upon stimulation with LPS or INF- $\gamma$ (42). Unfortunately, epidemiological data from Eskimos on morbidity and mortality due to other causes than heart diseases are complicated by influences of other factors such as sanitation. For example, Northern Indians and Inuit children are particularly prone to recurrent persistent chest infections (43). Although the authors suggested weakness in cellular immunity as a contributing factor, the influence of other factors such as sanitation cannot be ruled out. Eskimos also have an increased incidence of certain but not all types of cancers (43). Taken together, however, these observations suggest that our findings might have clinical significance. A recent report also provides indirect evidence that the changes in cell-mediated immunity observed in this study can have significant effects on incidence of infectious diseases. Chandra (44) showed that increases in indexes of $T$ cell-mediafed function in healthy elderly, after dietary supplementation, were associated with decreased morbidity due to infectious diseases.

It is interesting to note that in the present study feeding low-fat, low-fish diet enriched in plant-derived (n-6) and (n-3) PUFA had either no effect on the immunologic parameters measured (delayed-type hypersensitivity skin response, GMCSF, and IL-6) or enhanced them (mitogenic response, IL-1, and TNF). A significant decrease in the percentage of CD8+ cells was also observed. The observation that a low-fat, low-fish diet resulted in a significant increase in mitogenic responses and cytokine production indicates that, contrary to the previous speculations, on the basis of animal experiments (3-6), plant-derived PUFA, when fed in the context of a low-fat diet, do not suppress the immune response, rather they can have a modest stimulatory effect.

The low-fat, high-fish diet differed from the baseline in total fat content, saturated, monounsaturated, polyunsaturated fatty acids, cholesterol, and carbohydrate. It is unlikely that the decreased immunologic responses associated with the high-fish diet are because of a decrease in total fat content since decreases in total fat have been shown to enhance the immune response $(5,45,46)$. In our study, consumption of low-fat, low-fish diet (lower in fat content than the baseline diet as well) did not reduce the immunologic responses measured, rather, it was associated with an increase in some parameters. Since the low-fat, low-fish diet, which contained the same amount of total PUFA ( $10 \%)$ and (n-6) PUFA ( $8 \%$ ) but a lower amount of fish-derived ( $\mathrm{n}-3)$ PUFA $(0.13 \%$ of calories or $0.27 \mathrm{~g} / \mathrm{d}$ vs. $0.54 \%$ of calories or $1.23 \mathrm{~g} / \mathrm{d}$ EPA and DHA) than low-fat, 
high-fish diet, did not decrease immune responses, the effects observed are likely because of fish-derived ( $n-3)$ PUFA. This is supported by data from our laboratory as well as that of others, which showed fish-oil supplementation decreases ex vivo cytokine production $(11,12)$ and mitogenic response $(11,47)$. Three of the subjects who had completed the high-fish phase of the study also participated in the low-fish phase. The immunologic changes of these subjects reflected each of the two dietary phases. For example, they showed a decrease in delayed-type hypersensitivity skin response after the low-fat, high-fish diet and exhibited no change in delayed-type hypersensitivity skin response after the low-fat, low-fish diet.

In the present study, feeding a low-fat, high-fish diet caused a $313 \%$ increase in plasma EPA, $73 \%$ increase in plasma DHA, and $100 \%$ increase in linolenic, and a 28 and $82 \%$ decrease in $\mathrm{AA}$ and AA/EPA ratios, respectively. These were associated with a significant decrease in $\mathrm{PGE}_{2}$ production. Furthermore, a significant correlation between changes in EPA and a decrease in delayed-type hypersensitivity skin response was observed ( $r$ $=0.66, P=0.05)$. No correlation was observed between delayed-type hypersensitivity skin response and $18: 2 n-6$ or $20: 4 n-$ 6. Consumption of a low-fat, low-fish diet containing $2 \%$ $18: 3 n-3$ caused a significant increase in plasma linolenic (115\%), a significant but substantially lesser increase in plasma EPA (54\%), no significant change in DHA, and significant but small decreases in AA (12\%) and in AA/EPA ratios (38\%). This suggests that a substantial change in EPA, DHA, and AA/ EPA ratio is needed before the decrease in cytokine production, mitogenic response, and delayed-type hypersensitivity skin response are observed. It is interesting to note that, in our previous studies supplementation of EPA and DHA, $4.8 \mathrm{~g} / \mathrm{d}$ for $6 \mathrm{wk}$ or $2.4 \mathrm{~g} / \mathrm{d}$ for $12 \mathrm{wk}$ provided in the form of fish-oil capsules, also caused a significant decrease in cytokine production (young and old subjects) and mitogenic response (old subjects), which was associated with 88 and $91 \%$ decrease, respectively, in AA/EPA ratio $(11,12)$. Decreased mitogenic response in healthy subjects after consumption of fish oil was also reported by Kramer et al. (48). However, Payan et al. (49) found an increase in PHA-induced $\mathrm{T}$ cell proliferation in asthma patients and Kremer et al. (35) reported enhanced mitogenic response in patients with rheumatoid arthritis after fish-oil supplementation. The different effects observed by Payan et al. (49) and Kremer et al. (35), after consumption of fish oil, on mitogenic response compared with those reported in the present study and that of Kramer et al. (48) might be due to differences in health status of subjects used in these studies.

The observed immunologic changes induced by low-fat, high-fish diet are unlikely due to decreases in $\mathrm{PGE}_{2}$ production, as $\mathrm{PGE}_{2}$ suppresses IL-1, TNF, and IL-2 production as well as proliferation to mitogens (50). We recently showed that $\mathrm{PGE}_{3}$ added in vitro to peripheral blood mononuclear cells in the presence of a $\mathrm{T}$ cell mitogen decreases lymphocyte proliferation more than $\mathrm{PGE}_{2}(51)$. Thus the suppressive effects of $(\mathrm{n}-$ 3) PUFA-enriched diets may be due to the formation of EPAderived eicosanoids such as $\mathrm{PGE}_{3}$. (n-3) PUFA have been shown to compromise tocopherol status (26), a nutrient needed for normal maintenance of the immune response. Plasma tocopherol levels did not change in our subjects consuming low-fat, high-fish diets, however, the tocopherol/ PUFA ratio was significantly reduced. Furthermore, Meydani et al. (52) showed that supplementation with $2.4 \mathrm{~g} / \mathrm{d}$ of (n-3) PUFA for 3 mo increased plasma lipid peroxide levels despite no significant change in plasma tocopherol levels. Products of lipid peroxidation such as $\mathrm{H}_{2} \mathrm{O}_{2}$ were shown to suppress lymphocyte proliferation (53). Therefore, a rise in lipid peroxide level induced by ( $n-3)$ PUFA could contribute to the decrease in mitogenic and delayed-type hypersensitivity skin test responses observed in this study. The increase in mitogenic responses and cytokine production by a low-fat, low-fish diet can be due to a decrease in total fat intake or other fatty acid changes. This is supported by the studies of Hebert et al. (45) and Barone et al. (46) who showed increase in natural killer cytotoxicity when subjects were instructed to consume low-fat diets. Further studies are needed to elucidate this.

In conclusion, our results show that long-term feeding of low-fat, low-cholesterol diets enriched in PUFA have significant effects on in vitro and in vivo indexes of immune and inflammatory responses. A low-fat diet enriched in fish-derived ( $n-3)$ PUFA decreases several indexes of the immune response whereas a low-fat diet enriched in plant-derived (n-6) and (n3) PUFA has no effect or increases some indexes of the immune response in human subjects. The decrease in cytokine production by fish-derived (n-3) PUFA may contribute to the antiatherogenic and anti-inflammatory effects of these diets. The clinical significance of low-fat, high-fish diet-induced decrease in indexes of cell-mediated immunity (delayed-type hypersensitivity skin response, mitogenic response, and percentage of CD4+ cells) or low-fat, low-fish diet-induced modest increase in some indexes of immune response (TNF, IL-1, and mitogenic response) needs to be further investigated. Thus, in addition to hypolipidemic effects of these diets, other changes induced by these diets in immune and inflammatory parameters should be taken into consideration when population-based recommendations are made.

\section{Acknowledgments}

The authors are thankful to the staff of the USDA-HNRCA Metabolic Research Unit for their assistance in recruiting, admitting, care of subjects, and diet preparation; Dr. Judith Nerad and Ms. Lisa Gualtieri for technical assistance; and Karin Nauth, Angela Park, and Jennifer Munnis for preparation of this manuscript. Special thanks go to our study subjects for their cooperation and dedication.

Supported by National Institutes of Health grants HL39326 and AI 15614, a gift from Best Foods, a division of CPC Inc. and Van den Bergh Foods, and USDA contract AG09140-03.

\section{References}

1. National Research Council, Diet and Health. 1984. Implications for Reducing Chronic Disease Risk. Report of the Committee on Diet and Health, Food and Nutrition board. National Academy Press, Washington, DC.

2. National Cholesterol Education Program Expert Panel. 1988. Detection, evaluation, and treatment of high blood cholesterol in adults. Arch. Intern. Med. 148:36-69.

3. Johnston, P. V., and L. A. Marshall. 1984. Dietary fat, prostaglandins and the immune response. Prog. Food Nutr. Sci. 8:3-25.

4. Erickson, K. L. 1986. Dietary fat modulation of immune response. Int. J. Immunolpharmacol. 8:529-543.

5. Dupont, J., P. J. White, M. P. Carpenter, E. J. Schaefer, S. N. Meydani, C. E. Elson, M. Woods, and S. L. Gorbach. 1990. Food uses and health effects of corn oil. J. Am. Coll. Nutr. 9:438-470.

6. Meydani, S. N., A. Lichtenstein, P. J. White, S. M. Goodnight, C. E. Elson, M. Woods, S. L. Gorbach, and E. J. Schaefer. 1991. Food uses and health effects of soybean and sunflower oil. J. Am. Coll. Nutr. 10:406-428.

7. Libby, P., S. J. C. Warner, and G. B. Friedman. 1988. Interleukin-1. A mitogen for human vascular smooth muscle cells that induces the release of growth inhibitory prostanoids. J. Clin. Invest. 81:487-498.

8. Bevilacqua, M. P., J. S. Pober, M. E. Wheeler, R. S. Cotran, and M. A. 
Gimbrone. 1985. Interleukin-1 acts on cultured human vascular endothelium to increase the adhesion of polymorphonuclear leukocytes, monocytes and related leukocyte cell lines. J. Clin. Invest. 76:2003-2011.

9. Nawroth, P. P., and D. M. Stern. 1986. Modulation of endothelial cell hemostatic properties by tumor necrosis factor. J. Exp. Med. 163:740-745.

10. Warner, S. J. C., and P. Libby. 1989. Human vascular smooth muscle cells: target for and source of tumor necrosis factor. J. Immunol. 142:100-109.

11. Meydani, S. N., S. Endres, M. M. Woods, B. R. Goldin, C. Soo, A. MorrillLabrode, C. A. Dinarello, and S. L. Gorbach. 1991. Oral (n-3) fatty acid supplementation supresses cytokine production and lymphocyte proliferation: comparison between young and older women. J. Nutr. 121:547-555.

12. Endres, S., R. Ghorbani, V. E. Kelley, K. Georgilis, G. Lonnemann, J. W. M. van der Meer, J. G. Cannon, T. S. Rogers, M. S. Klempner, P. C. Weber, et al. The effect of dietary supplementation with n-3 polyunsaturated fatty acids on the synthesis of interleukin-1 and tumor necrosis factor by mononuclear cells. 1989. N. Engl. J. Med. 320:265-271.

13. Exler, J., and J. L. Welhrauch. 1986. Provisional tables on the content of n-3 fatty acid and other fat components in selected foods. USDA Human Nutrition Information Service. UNIS/PT-103.

14. Lesourd, B. M., A. Wang, and R. Moulias. 1985. Serial delayed cutaneous hypersensitivity skin testing with multiple recall antigens in healthy volunteers: booster effect study. Ann. Allergy 55:724-735.

15. Dinarello, C. A., G. Lonnenmann, R. Maxwell, and S. Shaldon. 1987. Ultrafiltration to reject human interleukin-1-induced substances derived from bacterial cultures. J. Clin. Microbiol. 25:1233-1238.

16. Gillis, S., M. M. Fern, W. Ou, and K. A. Smith. 1978. T-cell growth factor: parameters of production and a quantitative micro-assay for activity. J. Immunol. 120:2027-2032.

17. Schindler, R., J. Mancilla, S. Endres, R. Ghorbani, S. C. Clark, and C. A Dinarello. 1990. Correlation and interactions in the production of IL-6, IL-1 and TNF in human blood mononuclear cells: IL-6 suppresses IL-1 and TNF. Blood. 75:40-47.

18. Katzen, N. A., G. M. Segal, E. Vannier, J. L. Nerad, M. S. Klemper, and C. A. Dinarello. 1991. Comparison of granulocyte-macrophage colony stimulating factor and interleukin-1 production from human peripheral blood mononuclear cells as measured by specific radioimmunoassays. Eur. Cytokine Network. In press.

19. Endres, S., R. Ghorbani, G. Lonnemann, J. W. M. van der Meer, and C. A. Dinarello. 1988. Measurement of immunoreactive interleukin-1, for human mononuclear cells: optimization of recovery, intrasubject consistency and comparison with interleukin-1 and tumor necrosis factor. Clin. Immunol. Immunopathol. 49:424-438.

20. Van der Meer J. W. M., S. Endres, G. Lonnemann, J. G. Cannon, T. Ikejima, S. Okusawa, J. A. Gelfand, and C. A. Dinarello. 1988. Concentrations of immunoreactive human tumor necrosis factor alpha produced by human mononuclear cells in vitro. J. Leukocyte Biol. 43:216-223.

21. McCosh, E. J., D. L. Meyer, and J. Dupont. 1976. Radioimmunoassay of prostaglandin $\mathrm{E}_{1}, \mathrm{E}_{2}, \mathrm{~F}_{2}$ in unextracted plasma, serum and myocardium. Prostaglandins. 12:472-486.

22. Meydani, S. N., G. Yogeeswaran, S. Liu, S. Baskar, and M. Meydani. 1988. Fish oil and tocopherol induced changes in natural killer cell mediated cytotoxicity and $\mathrm{PGE}_{2}$ synthesis in young and old mice. J. Nutr. 118:1245-1252.

23. Brown, B. A. 1984. Hematology: Principles and Procedures. 4th ed. Lea and Febiger, Philadelphia, PA.

24. Herzenberg, L. A. 1978. Analysis and separation using fluorscence-activated cell sorter (FACS). In Handbook of Experimental Immunology. 3rd edition. D. M. Weir, editor. Blackwell, Oxford, England. 221-225.

25. Bieri, J. G., T. J. Tollinery, and G. L. Catigani. 1979. Simultaneous determination of alpha-tocopherol and retinol in plasma or red cells by high pressure liquid chromatography. Am. J. Clin. Nutr. 32:2143-2149.

26. Meydani, S. N., A. C. Shapiro, M. Meydani, J. McCauley, and J. B. Blumberg. 1987. Effect of age and dietary fat (fish oil, corn oil, and coconut oil) on tocopherol status of C57BL/6Nia mice. Lipids. 22:345-350.

27. SAS Institute, Inc. SAS User's Guide: 1985. Statistics. Version 5 edition. Cary, NC.

28. Lichtenstein, A. H., J. Millar, J. R. McNamera, J. M. Ordovas, and E. J. Schaefer. 1990. Long-term lipoprotein response to the NCEP step-2 diet enriched in $\mathrm{n}-3$ fatty acids. Circulation. 82:III-475.

29. Lichtenstein, A. H., J. S. Millar, J. R. McNamara, J. L. Jenner, H. Rasmussen, J. M. Ordovas, and E. J. Schaefer. 1991. Effect of long-term consumption of an NCEP step 2 diet on fasting and plasma lipoprotein concentrations. FASEB (Fed. Am. Soc. Exp. Biol.) J. 5:1070a. (Abstr.)
30. Bevilacqua, M. P., Pober, J. S., G. R. Majeau, and R. S. Cotran, Jr. MAG. 1984. Interleukin-1 (IL-1) induces biosynthesis and cell surface expression of procoagulant activity in human vascular endothelial cells. J. Exp. Med. 160:618623.

31. Nachman, R. L., Hajjar, K. A., R. L. Silverstein, and C. A. Dinarello. 1986. Interleukin-1 induces endothelial cell synthesis of plasminogen activator inhibitor. J. Exp. Med. 163:1595-1600.

32. G. Ku, C. E. Thomas, A. L. Akeson, and R. L. Jackson. 1991. Induction of interleukin 1 beta expression from human peripheral blood monocyte-derived macrophages by 9-hydroxyoctadecadienoic acid. J. Biol. Chem. In press.

33. Dyberg, J., and H. O. Bang. 1979. Haemostatic function and platelet polyunsaturated fatty acids in Eskimos. Lancet. 2:433-435.

34. Kromhout, D., E. B. Boschieter, C. De Lezemme Coulander. 1985. The inverse relationship between fish consumption and 20 year mortality from coronary heart disease. N. Engl. J. Med. 116:433-435.

35. Kremer, J. M., W. Jubiz, A. Michalek, R. L. Rymes, L. E. Bartholomew, J. Bigaouette, M. Timchalk, D. Beeler, and L. Lininger. 1985. Fish oil fatty acid supplementation in active rheumatoid arthritis. A double blinded, controlled crossover study. Ann. Intern. Med. 106:497-502.

36. Stenson, W. F., D. Cort, J. Rodgers, R. Burakoff, K. DeSchryver-Kecskemeti, T. L. Gramlich, and W. Beeken. 1992. Dietary supplementation with fish oil in ulcerative colitis. Ann. Intern. Med. 16:609-614.

37. Roberts-Thomspon, L. C., S. Whittinghan, U. Youngchairjad, and I. R. Mackay. 1974. Aging, immune response and mortality. Lancet 2:368-370.

38. Wayne, S. J., R. L. Rhyne, P. J. Garry, and J. S. Goodwin. 1990. Cell-mediated immunity as a predictor of morbidity and mortality in the aged. J. Gerontol. Med. Sci. 45:M45-M48.

39. Chang, H. R., A. G. Dulloo, I. R. Vladoianu, P. F. Piguet, D. Arsenijevic, L. Girardier, and J. C. Pechere. 1992. Fish oil decreases natural resistance of mice to infection with salmonella typhimurium. Metab. Clin. Exp. 41:1-2.

40. Berdanier, C. D., B. Johnson, D. K. Hartle, and W. Crowell. 1992. Life span is shortened in BHE/cdb rats fed a diet containin 9\% menhaden oil and $1 \%$ corn oil. J. Nutr. 122:1309-1317.

41. D'Ambola, J. B., E. E. Aeberhard, N. Trang, S. Gaffar, C. T. Barrett, and M. P. Sherman. 1991. Effect of dietary (n-3) and (n-6) fatty acids on in vivo pulmonary bacteral clearance by neonatal rabbits. J. Nutr. 121:1262-1269.

42. Hubbard, N. E., S. D. Somers, and K. L. Erickson. 1991. Effect of dietary fish oil on developmental and selected functions of murine inflammatory macrophages. J. Leukocyte Biol. 49:592-598.

43. Hilds, J. A., and O. Schaefer. 1984. The changing picture of neoplastic disease in the western and central Canadian Arctic (1950-1980). Can. Med. Assoc. J. 130:25-32.

44. Chandra, R. K. 1992. Effect of vitamin and trace-element supplementation on immune responses and infectious in elderly subjects. Lancet 340:11241127.

45. Hebert, J. R., J. Barone, M. M. Reddy, and J. Y. C. Backlund. 1990. Natural killer cell activity in a longitudinal dietary fat intervention trial. Clin. Immunol. Immunopathol. 54:103-116.

46. Barone, J., J. R. Hebert, and M. M. Reddy. 1989. Dietary fact and naturalkiller-cell activity. Am. J. Clin. Nutr. 50:861-867.

47. Yoshino, S., and E. F. Ellis. 1987. Effect of fish-oil-supplemented diet on inflammation and immunological processes in rats. Int. Arch. Allergy Appl. Immunol. 84:233-240.

48. Kramer, T. R., N. Schoene, L. W. Douglass, J. T. Judd, R. Ballard-Barbash, P. R. Taylor, H. N. Bhagavan, and P. P. Nair. 1991. Increased vitamin E intake restores fish-oil-induced suppressed blastogenesis of mitogen-stimulated $\mathrm{T}$ lymphocytes. Am. J. Clin. Nutr. 54:896-902.

49. Payan, D. G., M. Y. S. Wong, and T. Chernov-Rogan. 1986. Alterations in human leukocyte function induced by ingestion of eicosapentaenoic acid. $J$. Clin. Immunol. 6:402-410.

50. Goodwin, J. S., and D. R. Webb. 1980. Regulation of the immune response by prostaglandins. Clin. Immunol. Immunopathol. 15:106-122.

51. Shapiro A. C., D. Wu, S. N. Meydani. 1993. Eicosanoids derived from arachidonic and eicosapentaenoic acids inhibit $\mathrm{T}$ cell proliferative response. Prostaglandins. 45:229-240.

52. Meydani, M., F. Natiello, B. Goldin, N. Free, M. Woods, E. Schaefer, J. Blumberg, and S. L. Gorbach. 1990. Effect of long-term fish oil supplementation on vitamin E status and lipid peroxidation in women. J. Nutr. 121:484-491.

53. Zoschke, D. C., and R. P. Messner. 1984. Suppression of human lymphocyte mitogenesis mediated by phagocyte-released reactive oxygen species; comparative activities in normal and in chronic granulamatous disease. Clin. Immunol. Immunopathol. 49:670-692. 